Report No.: ORNL/TM-2001/166

\title{
Development of a Robust Model-Based Water Level Controller for U-Tube Steam Generator
}

\author{
A.M. Hasanul Basher \\ South Carolina State University \\ J. March-Leuba \\ Oak Ridge National Laboratory
}

September 2001

Prepared by the

Oak Ridge National Laboratory

Oak Ridge, Tennessee 37831

Managed by

UT-Battelle, LLC

For

U.S. Department of Energy

Under contract DE-AC05-00OR22725 


\section{DISCLAIMER}

This report was prepared as an account of work sponsored by an agency of the United States government. Neither the United States Government nor any agency thereof, nor any of their employees, makes any warranty, express or implied, or assumes any legal liability or responsibility for the accuracy, completeness, or usefulness of any information, apparatus, product, or process disclosed, or represents that its use would not infringe privately owned rights. Reference herein to any specific commercial product, process, or service by trade name, trademark, manufacturer, or otherwise, does not necessarily constitute or imply its endorsement, recommendation, or favoring by the United States Government or any agency thereof. The views and opinions of authors expressed herein do not necessarily state or reflect those of the United States Government or any agency thereof. 


\section{TABLE OF CONTENTS}

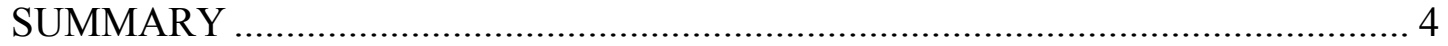

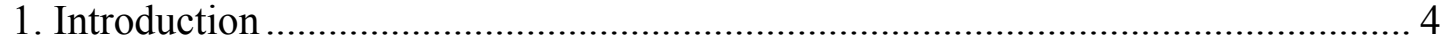

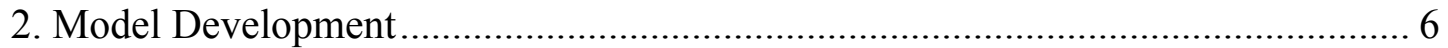

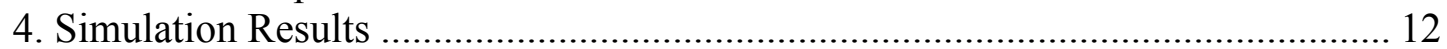

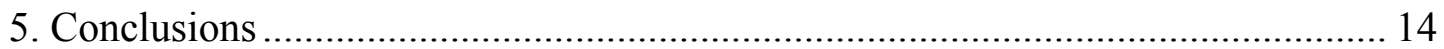

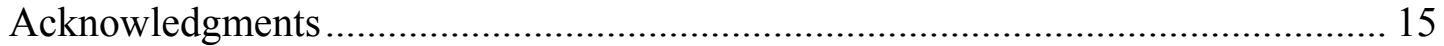

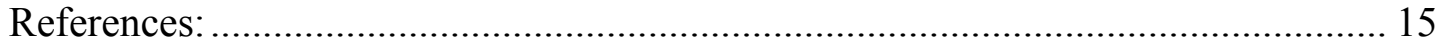

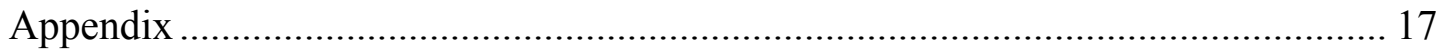




\section{SUMMARY}

Poor control of steam generator water level of a nuclear power plant may lead to frequent nuclear reactor shutdowns. These shutdowns are more common at low power where the plant exhibits strong non-minimum phase characteristics and flow measurements at low power are unreliable in many instances. There is need to investigate this problem and systematically design a controller for water level regulation. This work is concerned with the study and the design of a suitable controller for a U-Tube Steam Generator (UTSG) of a Pressurized Water Reactor (PWR) which has time varying dynamics. The controller should be suitable for the water level control of UTSG without manual operation from start-up to full load transient condition. Some preliminary simulation results are presented that demonstrate the effectiveness of the proposed controller. The development of the complete control algorithm includes components such as robust output tracking, and adaptively estimating both the system parameters and state variables simultaneously. At the present time all these components are not completed due to time constraints. A robust tracking component of the controller for water level control is developed and its effectiveness on the parameter variations is demonstrated in this study. The results appear encouraging and they are only preliminary. Additional work is warranted to resolve other issues such as robust adaptive estimation.

\section{Introduction}

For the steam generator (SG) in a nuclear power plant, the main goal of its control system is to maintain the SG water level at a desired value by regulating the feed-water flow rate. Conventional feed-water control schemes cannot provide satisfactory performance within the required wide operating range of 0 to $100 \%$ of the specified load. A large proportion of reactor shutdowns at operating nuclear plants, which causes a severe economic loss, has been mainly caused by ineffective feed-water control. Therefore, development of better control schemes is very important. A review of past PWR plant operation experiences indicates that unplanned reactor trips due to SG level control have been significant contributors to plant unavailability. During low power operation, the level control is complicated by the thermal reverse effects known as "shrink and swell". Due to the destabilizing vapor content in the tube bundle region, the water level measured in the downcomer temporarily reacts in a reverse manner to water inventory change. Increased feed-water flow adds mass to the SG, which would be expected to increase the measured downcomer water level, and does not increase it at high power. But at low power, the cold feed-water addition can cause a decrease in the vapor content of tube bundle, a shift in the liquid from the downcomer to tube bundle, and a temporary decrease in level (shrink). Similarly, a decrease in feed-water flow can cause a temporary increase in water level (swell). These reverse effects are confusing for either manual or automatic operation. The only true indication of water inventory change is the flow mismatch between steam and feed-water. 
The water level of the steam generator must not be allowed to rise too high in order to prevent the excessive moisture carryover and the pressure buildup of the containment in the break of secondary side flow loop. Also, the low water level should be prevented in order to avoid the uncovery of the U-tubes in the secondary side. Therefore, the control of the steam generator water level is important to determine power plant responses in the event of changes in the operating load. The proposed controller is designed to ensure a satisfactory automatic control for the SG water level from low power to full power.

Different approaches to the control of steam generator water level of PWR have been reported in the literature. Kothare et al. [1] and Kothare et al. [2] applied Model Predictive Control (MPC) technique for SG level control. MPC is an open-loop design procedure. This technique works as follows. At sampling time $\mathrm{k}$ a plant measurement of the output is obtained. An estimator takes the measured output value and the manipulated input to obtain the estimate of the plant state. An optimizer takes the estimated plant state and computes a sequence of control moves by minimizing an objective function. A more general Linear Quadratic Gaussian (LQG)/Loop Transfer Recovery (LTR)-based controller is proposed by Menon and Parlor [3]. The controller in [3] is developed using local linearization of the SG model and then gain-scheduled to cover the entire range. In their design the linearized model around each equilibrium point is scheduled and fitted as a function of the difference in the hot- and cold-leg temperatures of the UTSG primary side. Water level control of steam generator at low power using Model Reference Adaptive Control method is reported in [4]. In this work a dynamic reference model is used to generate the reference index of performance for the plant in terms of feed-water flow-rate, steam flow-rate and water level. $\mathrm{Na}$ [5] and $\mathrm{Na}$ and $\mathrm{No}$ [6] presented adaptive observer to simultaneously estimate the flow errors and the parameters of the steam generator model. These estimated parameters are then used to design the control action by minimizing a quadratic cost function. A discrete model is used in [4-6] and the controller is designed to work for low power. Research works on robust tracking and observer-based robust controller are reported in [7-10].

We use continuous time model of the plant and apply Linear Quadratic Regulator (LQR) technique to design an optimum controller that forces the plant output (water level) to follow a desired water level pattern. Our model is represented as a function of feed-water flow-rate, steam flow-rate, and water level unlike [3]. The detailed discussion on LQR technique is available in [11]. Robust tracking is achieved for a certain range of parameter drifts. MATLAB software package is used to generate computer simulation results. The results validate the effectiveness of the controller in water level control of the steam generator. We have attempted to develop a robust adaptive observer for the UTSG level control but due to time constraints it is not complete at this time. For various techniques on robust adaptive observer and optimum controller please refer to [12] and [13] respectively. 


\section{Model Development}

A steam generator shows complicated dynamic behaviors with nonlinear characteristics. Some theoretical models based on thermodynamic experiments and/or energy conservative equations have been developed to use for operator training simulator and accident analysis and so on. However, these are inadequate as mathematical models for designing controllers due to complexities. The controller design and the resulting controller performance on the actual plant are both strongly dependent on the accuracy of the mathematical model used to describe the plant. However, a highly accurate model is generally also highly complex and nonlinear, and therefore leads to difficulties in controller design. For the purpose of controller design, the model should be simple and at the same time relatively accurate in describing the principal dynamics of the U-Tube Steam Generator (UTSG). The difficulties in designing an effective level control system for the steam generator arise from a number of factors: (1) the inverse response behavior of the plant, particularly at low operating power due to the so-called "swell and shrink" effects; (2) variation of plant dynamics with operating power; (3) unreliable flow measurements at low power which preclude effective use of feed-forward control: (4) constraints on the throughputs of the main and bypass valves which operate on the manipulated variable, the feed-water flow-rate to the SG. In this study we use the model which has been widely used by many researchers [5] for control purposes. The model is a linear fourth-order model whose parameters depend on reactor power level. The transfer function relating the feed-water flow-rate and the steam flow-rate to the water level is given by,

$$
\begin{aligned}
Y(s) & =\frac{G_{1}}{s}\left(q_{w}(s)-q_{v}(s)\right)-\frac{G_{2}}{1+\tau_{2} s}\left(q_{w}(s)-q_{v}(s)\right) \\
& +\frac{G_{3} s}{\tau_{1}^{-2}+4 \pi^{2} T^{-2}+2 \tau_{1}^{-2} s+s^{2}} q_{w}(s)
\end{aligned}
$$

where,

$Y(s), q_{\mathrm{w}}(s)$, and $q_{\mathrm{v}}(s)$ are water level, feed-water flow-rate, and steam flow-rate respectively, and $\tau_{1}, \tau_{2}$, and $T$ are damping time constants and oscillation period respectively.

$$
\frac{G_{1}}{s} \text { is the mass capacity effect of the UTSG. It integrates the flow difference to }
$$
calculate the change in water level. This term accounts for the level change due to feed water inlet to steam generator and the steam outlet from it. This quantity means the actual water capacity which critically affects the removal capability of the primary heat. $G_{1}$ is a positive constant and does not depend on load. $-\frac{G_{2}}{1+\tau_{2} s}$ is the thermal negative effect caused by "swell and shrink". Since these phenomena exhibit exponential responses for step changes of the feed water flow-rate and the steam flow-rate, they are described by a 
first-order equation. $G_{2}$ is positive and dependent on load. As load increases $G_{2}$ decreases. The third term is the mechanical oscillation effect caused by the inflow of the feed-water to the UTSG. This is a mechanical oscillation term due to momentum of the water in the downcomer. All the water removed from the steam is returned to the downcomer and is recirculated. The recirculating water has large momentum acting against relatively small flow-rate changes. When the feed-water flow-rate is suddenly decreased, the water level in the downcomer falls initially and then begins to oscillate. This is due to the momentum of the water in the downcomer keeping the recirculating flow going down initially and then slowing down. The mechanical oscillation disappears completely after a small multiple of the damping time constant. The variable $G_{3}$ is positive.

We divide the steam generator dynamics into four linearized regions with respect to operating power level and assume that the dynamics vary linearly over these regions. These variations of the plant parameters with respect to power level are presented in th graphical form. The actual plant parameters may vary differently, so we study the performance of the controller under the situations when the parameter drifts from what is projected by linear interpolation. Systematic approaches such as LQR method is used to derive the control law where some objectives functions are minimized to derive an optimal controller. The main objective of the controller is to maintain the water level in the steam generator under various operating levels. We also show the effect of parameter drift on the water level through computer simulation results. To design the proposed controller we transform the plant dynamics into a suitable state-space form.

The state equations are defined as follows:

$$
\begin{aligned}
& \delta \dot{x}_{1}(t)=G_{1}\left(\delta q_{w}(t)-\delta q_{v}(t)\right) \\
& \delta \dot{x}_{2}(t)=-\tau_{2}^{-1} \delta x_{2}(t)-\frac{G_{2}}{\tau_{2}}\left(\delta q_{w}(t)-\delta q_{v}(t)\right) \\
& \delta \dot{x}_{3}(t)=-2 \tau_{1}^{-1} \delta x_{3}(t)+\delta x_{4}(t)+G_{3} \delta q_{w}(t) \\
& \delta \dot{x}_{4}(t)=-\left(\tau_{1}^{-2}+4 \pi^{2} T^{-2}\right) \delta x_{3}(t)
\end{aligned}
$$

and the output (water level) is

$$
\delta y_{p}(t)=\delta x_{1}(t)+\delta x_{2}(t)+\delta x_{3}(t)
$$

If we define $\delta x_{p}(t) \stackrel{\Delta}{=}\left[\delta x_{1} \delta x_{2} \delta x_{3} \delta x_{4}\right]^{T}$, the dynamics of the steam generator system can then be reduced to the following state-space equations:

$$
\begin{aligned}
& \delta \dot{x}_{p}(t)=A_{p} \delta x(t)+B_{p} \delta q_{w}(t)+F_{p} \delta q_{v}(t) \\
& \delta y_{p}(t)=C_{p} \delta x(t)
\end{aligned}
$$

where $A_{p}, B_{p}$, and $C_{p}$ matrices are given as: 


$$
A_{p}=\left[\begin{array}{cccc}
0 & 0 & 0 & 0 \\
0 & a_{22} & 0 & 0 \\
0 & 0 & a_{33} & a_{34} \\
0 & 0 & a_{43} & 0
\end{array}\right], \quad B_{p}=\left[\begin{array}{c}
b_{1} \\
b_{2} \\
b_{3} \\
0
\end{array}\right], \quad F_{p}=\left[\begin{array}{c}
d_{1} \\
d_{2} \\
0 \\
0
\end{array}\right], \quad C_{p}=\left[\begin{array}{llll}
1 & 1 & 1 & 0
\end{array}\right]
$$

where,

$$
\begin{aligned}
& a_{22}=-\tau_{2}^{-1}, a_{33}=-2 \tau_{1}^{-1}, a_{34}=1, a_{43}=-\left(\tau_{1}^{-2}+4 \pi^{2} T^{-2}\right), b_{1}=G_{1}, b_{2}=-G_{2} \tau_{2}^{-1}, \\
& b_{3}=G_{3}, d_{1}=-G_{1}, d_{2}=\frac{G_{2}}{\tau_{2}} .
\end{aligned}
$$

The approximate linearized model can be given by,

$$
\begin{aligned}
& \delta \dot{x}_{p}(t)=A_{0} \delta x_{p}(t)+B_{0} \delta u_{p}(t)+F_{0} \delta w(t) \\
& \delta y_{p}(t)=C_{0} \delta x(t)
\end{aligned}
$$

where $\delta u_{p}(t) \stackrel{\Delta}{=} \delta q_{w}(t)$ and $\delta w(t) \stackrel{\Delta}{=} \delta q_{v}(t)$.

In the subsequent derivations $\delta \mathrm{s}$ will be removed for clarity. We will write the system equations as:

$$
\begin{aligned}
& \dot{x}_{p}(t)=A_{0} x_{p}(t)+B_{0} u_{p}(t)+F_{0} w(t) \\
& y_{p}(t)=C_{0} x_{p}(t)
\end{aligned}
$$

where $x_{p}, q_{w}, q_{v}$, and $y_{p}$ are the variations in plant state, feed-water flow-rate, steam flowrate, and the system output.

One of the objectives is to design a state feedback controller so that the system is internally stable and its output (actual water level) asymptotically tracks the reference input (desired water level). This output tracking is achieved using a dynamic compensator through the introduction of a vector $q$ defined below.

$$
\dot{q}=y_{p}-y_{r}=C_{0} x_{p}-y_{r}
$$

where $y_{\mathrm{r}}$ is the reference input.

The state-space equations for the augmented system may be given by,

$$
\begin{aligned}
& \dot{x}_{p q}(t)=A_{p q} x_{p q}(t)+B_{p q} u_{p q}(t)+F_{p q} w(t)+H_{p q} y_{r} \\
& y_{p q}(t)=C_{p q} x_{p q}(t)
\end{aligned}
$$


where, $x_{p q}=\left[\begin{array}{ll}x_{p} & q\end{array}\right]^{T}, y_{p q}=y_{p}$ and

$$
A_{p q}=\left[\begin{array}{cc}
A_{0} & 0 \\
C_{0} & 0
\end{array}\right], B_{p q}=\left[\begin{array}{c}
B_{0} \\
0
\end{array}\right], C_{p q}=\left[\begin{array}{ll}
C_{0} & 0
\end{array}\right], F_{p q}=\left[\begin{array}{c}
F_{0} \\
0
\end{array}\right], \text { and } H_{p q}=\left[\begin{array}{c}
0 \\
-1
\end{array}\right]
$$

\section{Controller Design}

\section{Output Tracking:}

To minimize the effects of parameter approximation one leads to minimize the cost functional,

$$
J_{1}=\int_{t_{0}}^{\infty}\left[x_{p q}{ }^{T}(t) Q_{1} x_{p q}(t)+u_{p q}{ }^{T}(t) R_{1} u_{p}(t)\right] d t
$$

where $Q_{1}$ and $R_{1}$ are constant weighting matrices that must be selected by the designer. The constant state weighting matrix $Q_{0}$ is selected to be symmetric and at least positive semi-definite and the control weighting matrix $R_{1}$ is selected to be symmetric and positive definite. Under these assumptions the value of $J_{1}$ is nonnegative.

The optimal control vector $u_{p q}(t)$ is generated from the state perturbation $x_{p q}(t)$ by a linear constant gain feedback

$$
u_{p q}(t)=-K x_{p q}(t)
$$

where $K$ is a constant feedback gain matrix given by

$$
K=R_{1}^{-1} B_{p q}{ }^{T} P_{1}
$$

and $P_{1}$ is a constant symmetric positive definite matrix which is the solution of the algebraic matrix Riccati equation,

$$
P_{1} A_{p q}-A_{p q}^{T} P_{1}-Q_{1}+P_{1} B_{p q} R_{1}^{-1} B_{p q}^{T} P_{1}=0
$$

Then we can show that

$$
u_{p q}=-K x_{p q}(t)=-K_{1} x_{p}-K_{2} q \text { where } K=\left[\begin{array}{ll}
K_{1} & K_{2}
\end{array}\right]
$$

The existence and uniqueness of solution for the above equation are guaranteed by the following assumptions:

1. $\left(A_{p q}, B_{p q}\right)$ is a controllable pair,.

2. $\left(A_{p q}, Q_{l}^{1 / 2}\right)$ is an observable pair. 
Under these assumptions the closed loop system

$$
\dot{x}_{p q}(t)=\left(A_{p q}-B_{p q} K\right) x_{p q}(t)+F_{p q} w(t)+H_{p q} y_{r}
$$

is asymptotically stable. This implies $\dot{q} \rightarrow 0$ as $t \rightarrow \infty$ and $y_{p} \rightarrow y_{r}$.

The complete system with tracking controller can be represented by the following block diagram.

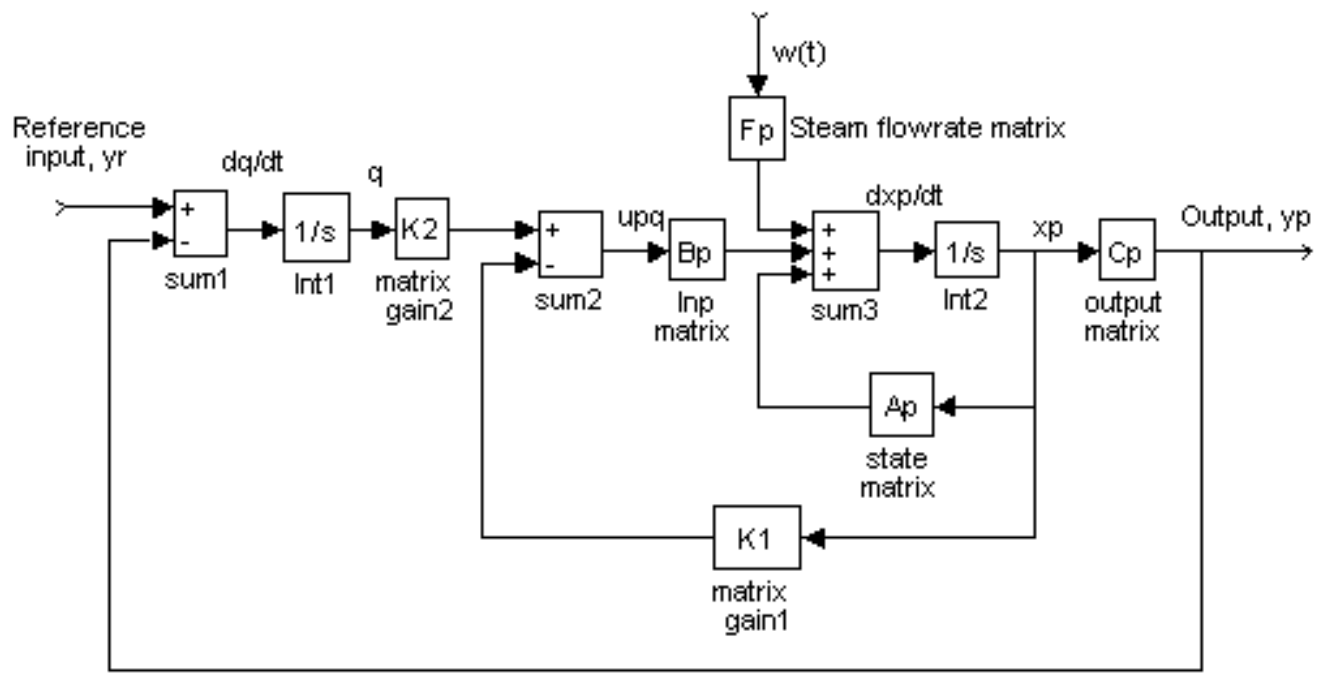

Fig. 1. Block diagram of the control system for output tracking

The dynamic parameters with respect to operating power linearized at different power level [14] is shown in the table below:

Table 1

\begin{tabular}{|l|c|c|c|c|c|}
\hline$q_{\mathrm{v}}(\mathrm{kg} / \mathrm{s})$ & 57.4 & 180.8 & 381.7 & 660 & 1435 \\
\hline $\mathrm{P}(\%$ power $)$ & 5 & 15 & 30 & 50 & 100 \\
\hline$G_{1}$ & 0.058 & 0.058 & 0.058 & 0.058 & 0.058 \\
\hline$G_{2}$ & 9.63 & 4.46 & 1.83 & 1.05 & 0.47 \\
\hline$G_{3}$ & 0.181 & 0.226 & 0.310 & 0.215 & 0.105 \\
\hline$\tau_{1}$ & 41.9 & 26.3 & 43.4 & 34.8 & 28.6 \\
\hline$\tau_{2}$ & 48.4 & 21.5 & 4.5 & 3.6 & 3.4 \\
\hline$T$ & 119.6 & 60.5 & 17.7 & 14.2 & 11.7 \\
\hline
\end{tabular}

The elements of $A_{p}$, and $B_{p}$ matrices are graphed below to show their variations with operating power. 


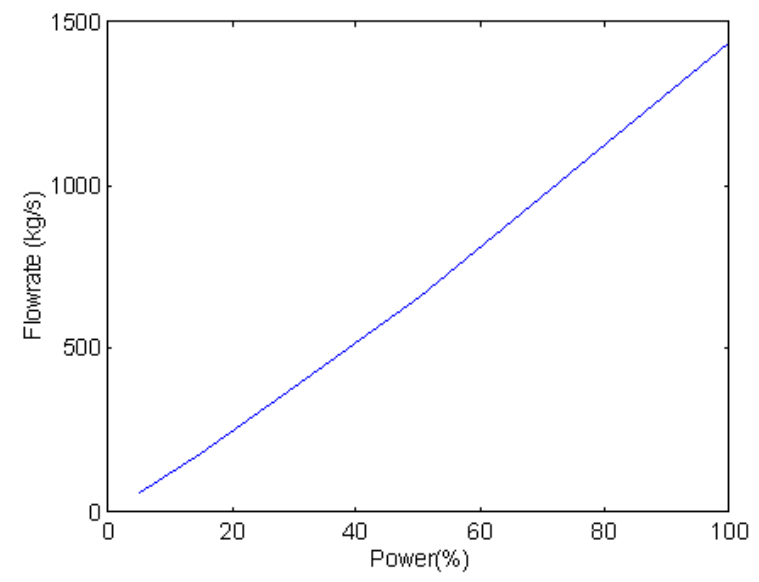

Fig. 2. Steam flowrate variation with power

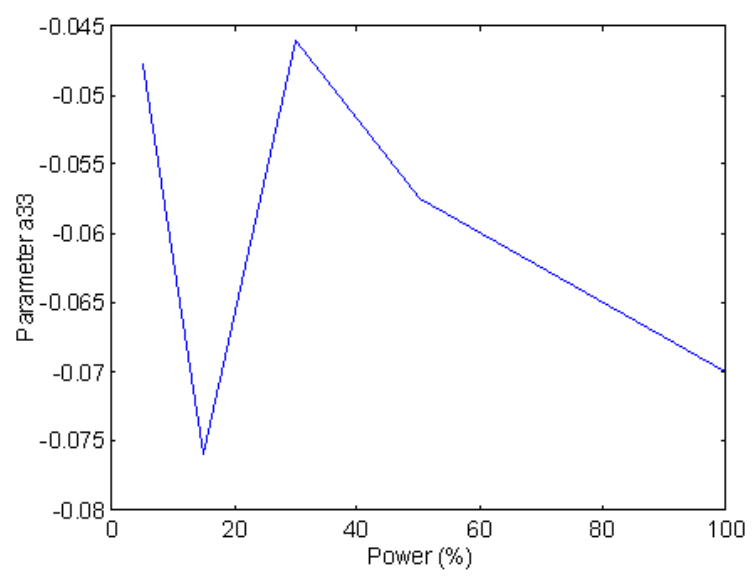

Fig. 4. Variation of element a33 with power

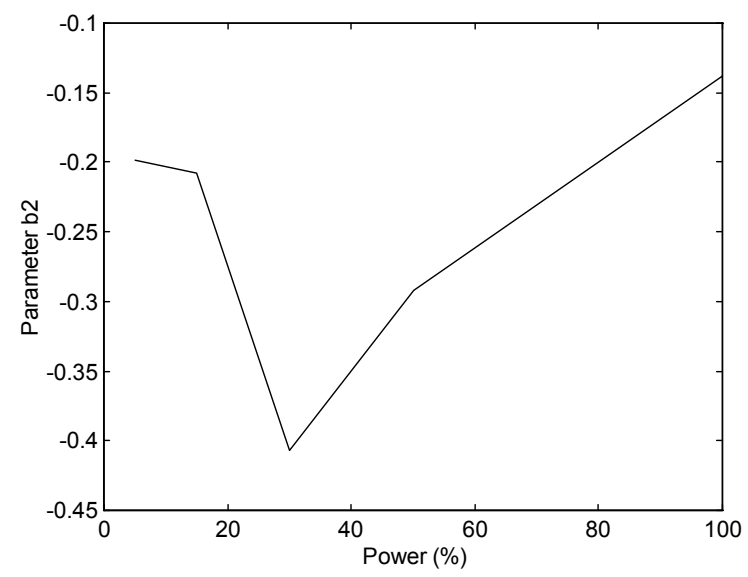

Fig. 6. Variation of element b2 with power

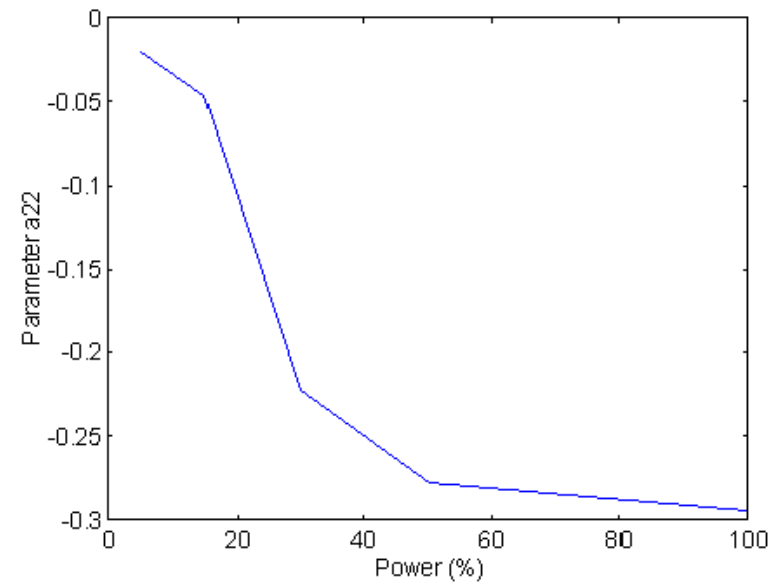

Fig. 3. Variation of element a22 with power

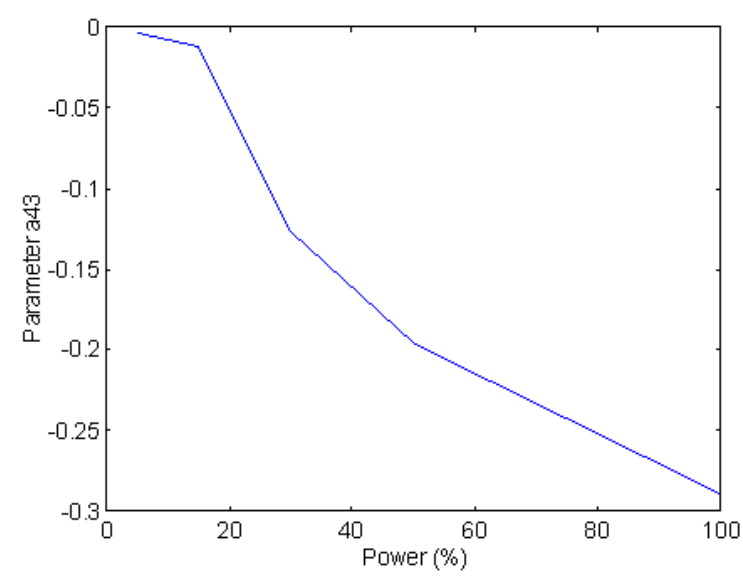

Fig. 5. Variation of element a43 with power

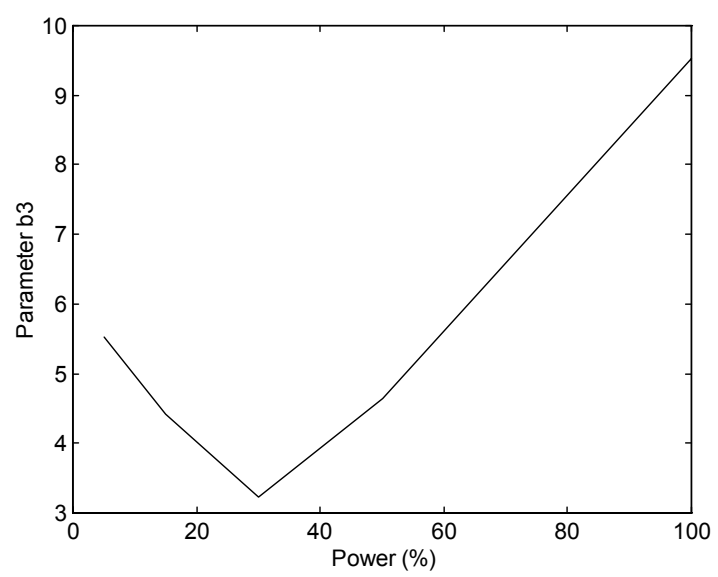

Fig. 7. Variation of element $b 3$ with power 


\section{Simulation Results}

We used a linear parameter varying model of UTSG of which parameters depends on the reactor power level. The model is linearized over four regions. The regions are divided according to operating power as: Region I for $0 \% \leq$ power $\leq 15 \%$, Region II for $15 \% \leq$ power $\leq 30 \%$, Region III for $30 \% \leq$ power $\leq 50 \%$, and Region IV for $50 \% \leq$ power $\leq 100 \%$. Over each region the elements of model matrices are assumed to vary linearly. These elements over each of these regions are obtained from the graph shown in figures $3,4,5,6$, and 7 . The simulation studies are carried out for instances when the actual plant parameters drift from the linearized model parameters. It can be seen that variation of element $b_{2}$ of $B_{\mathrm{p}}$ matrix has the most destabilizing effect on the system response. This is because it contains the term $G_{2}$ and $\tau_{2}$ whose value determine the nonminimum phase characteristic of the steam generator. The simulation results are displayed in order to show the effects of these two parameters particularly on the effectiveness of the controller and the quality of the system response. As the power of operation becomes higher the effect of perturbation of parameters becomes less. For each simulation, a step change of $10 \%$ in power is considered after the reactor has passed 100 seconds at steady-state condition. Since the power of operation is directly proportional to the steam flow-rate, a step change of $10 \%$ of steam flow-rate is taken as the load demand. We also assume that water flow-rate and steam flow-rate are equal before the change in power demand occurs, that means the change in water level is zero. Figs. 8 and 9 display the steam generator water level change, and water and steam flow-rate change respectively when the reactor operating power is at 5\% and no parameter perturbation is assumed. Figs. 10 and 11 portray the system response at the same power of operation $(5 \%)$ but the parameters $G_{2}$ and $\tau_{2}$ are perturbed such that the element $b_{2}$ is increased by $3 \%$. A substantial change in system behavior is noticed due to the drift of system parameter, such as larger overshoot and more oscillations before settling down to the desired value. Even when the parameter drifts, the controller is capable of maintaining the change in water level to zero and hence the water flow-rate change equals the steam flow-rate change. If the element $b_{2}$ drifts further the controller may not be robust enough to maintain the water level to the desired value. So we can say that the controller is robust

enough to maintain the desired system response if the parameter perturbation lies within certain bounds. A similar phenomenon is also observed when the operating power is at $10 \%$. For comparison, we have displayed the simulation results for $3 \%$ parameter perturbation at both $5 \%$ and $10 \%$ operating power (Figs. 10, 11, 12, and 13). At the 10\% operating power the response is better because the water level settles down to zero level faster at the cost of increased overshoot which is expected. We can conclude that the water level oscillations tend to reduce to zero level faster but the overshoot becomes larger as the operating power increases. A case when the parameter perturbation is large enough to cause sustained oscillations at $10 \%$ power is depicted in Fig. 14. For our model, these sustained oscillations occur when the parameter drifts by $5 \%$. We have further demonstrated in Figs. 15 and 16 that at 30\% operating power a similar transient behavior (compared to the cases of $5 \%$ and $10 \%$ operating power) can be achieved at larger $(30 \%)$ parameter perturbation. If we compare the responses portrayed in Figs. 16 and 17 , it is noticed that water level convergence to zero level is much quicker at the operating power of $50 \%$ than at $30 \%$ for the same perturbation amount. 


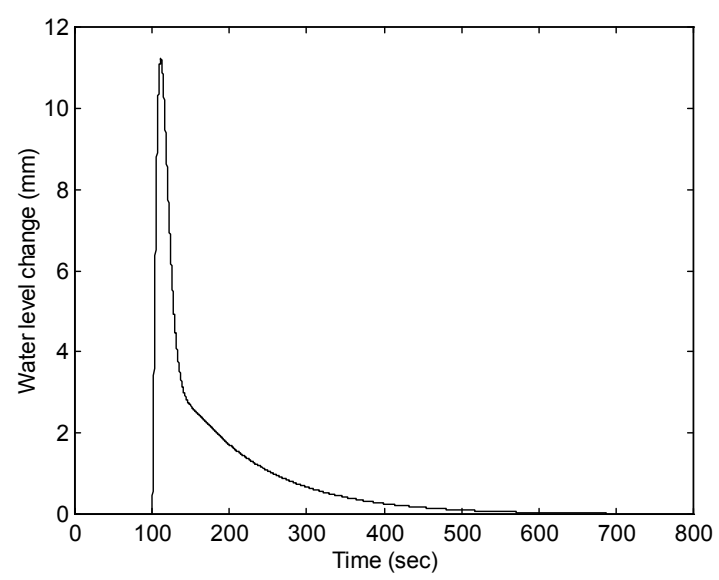

Fig. 8 . Water level Change at $5 \%$ power

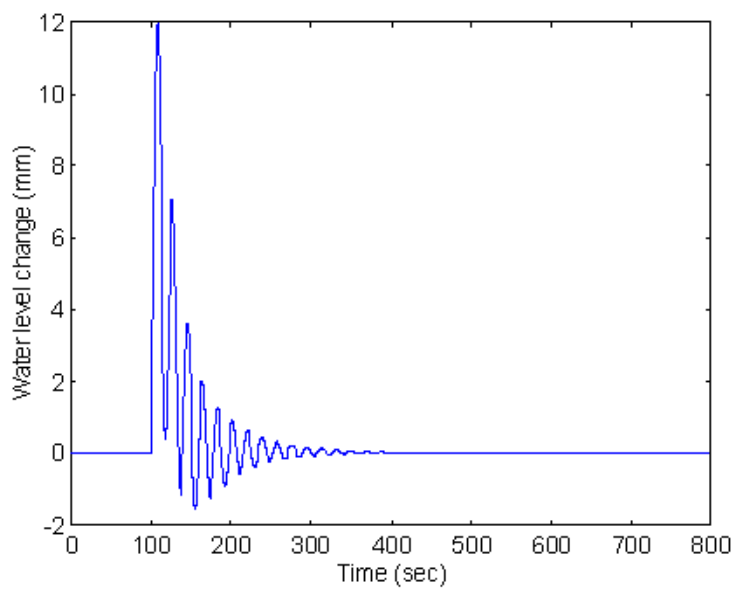

Fig. 10. Water level change at $5 \%$ power with $3 \%$ perturbation

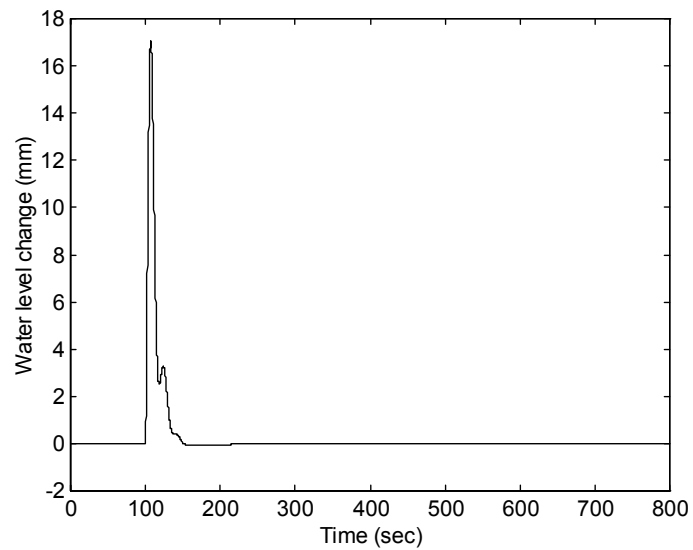

Fig. 12. Water level change at $10 \%$ power with $3 \%$ perturbation

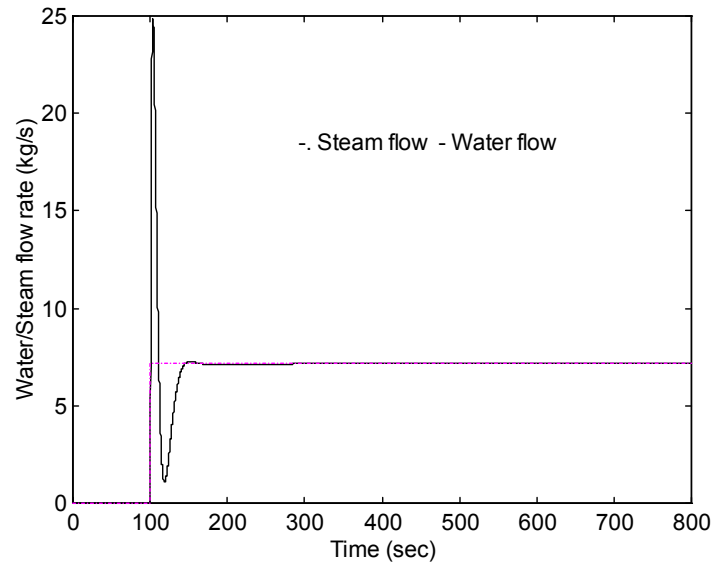

Fig. 9. Water/Steam flowrate change at 5\% power

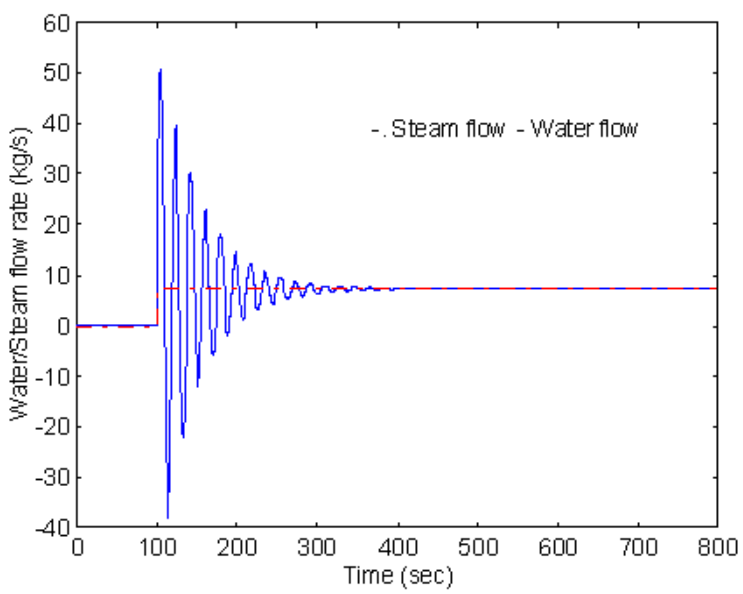

Fig. 11. Water/Steam flowrate change at 5\% power with $3 \%$ perturbation

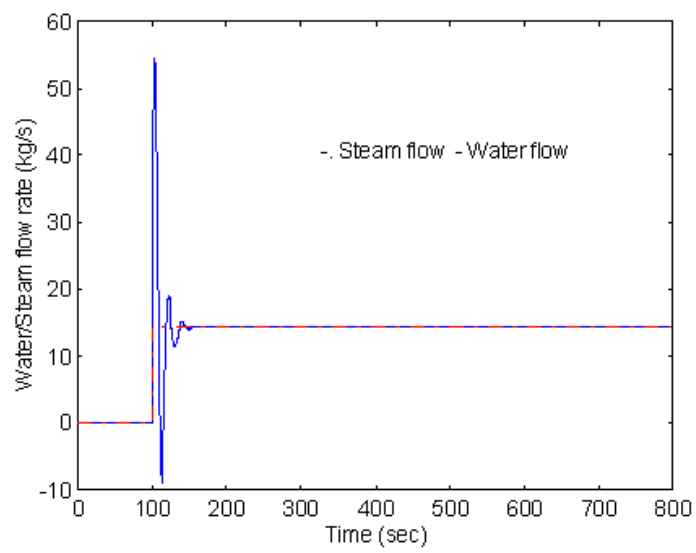

Fig. 13. Water/Steam flowrate change at $10 \%$ with $3 \%$ perturbation 


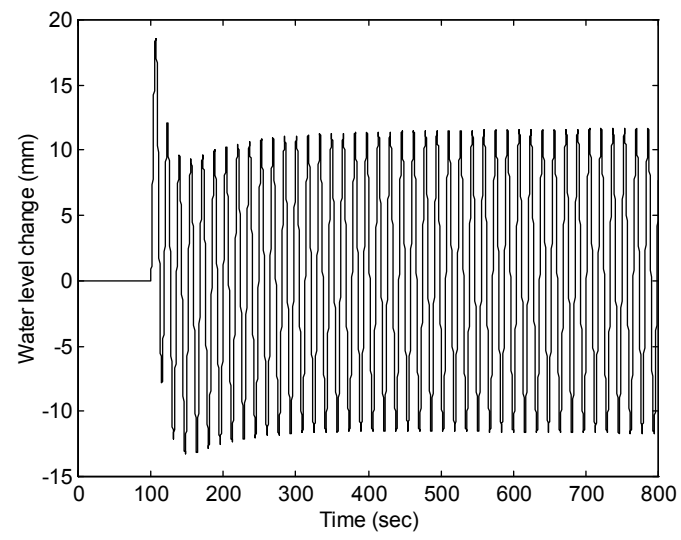

Fig. 14. Water/Steam flowrate change at 10\% power with $5 \%$ perturbation

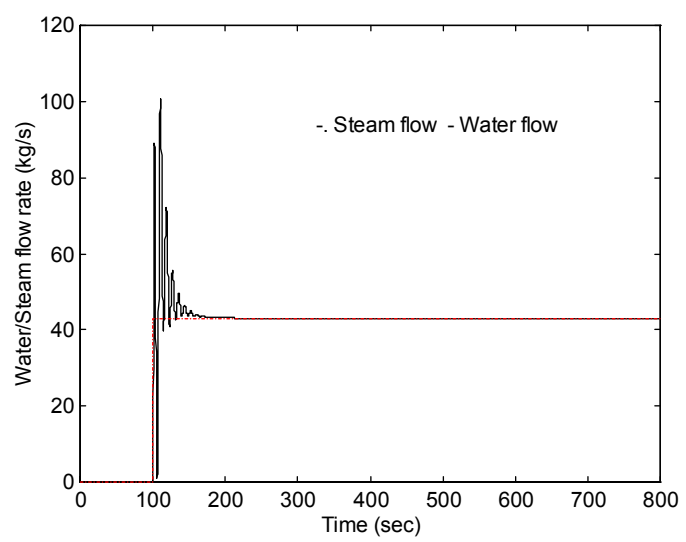

Fig. 16. Water/Steam flowrate change at 30\% power with $30 \%$ perturbation

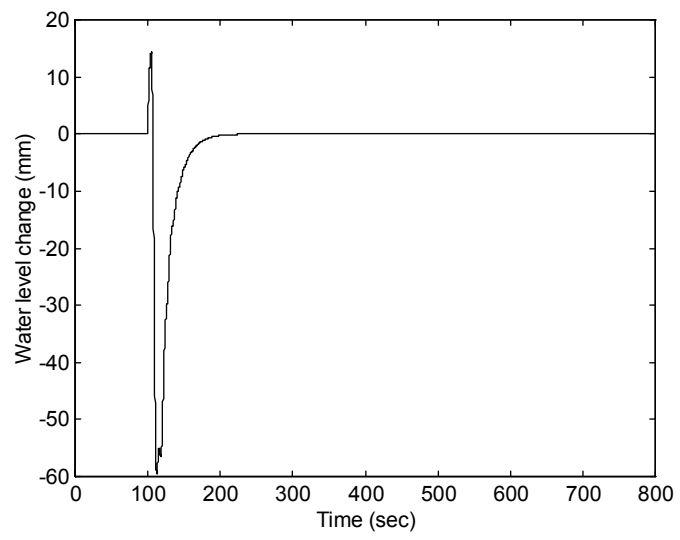

Fig. 15. Water level change at 30\% power with $30 \%$ perturbation

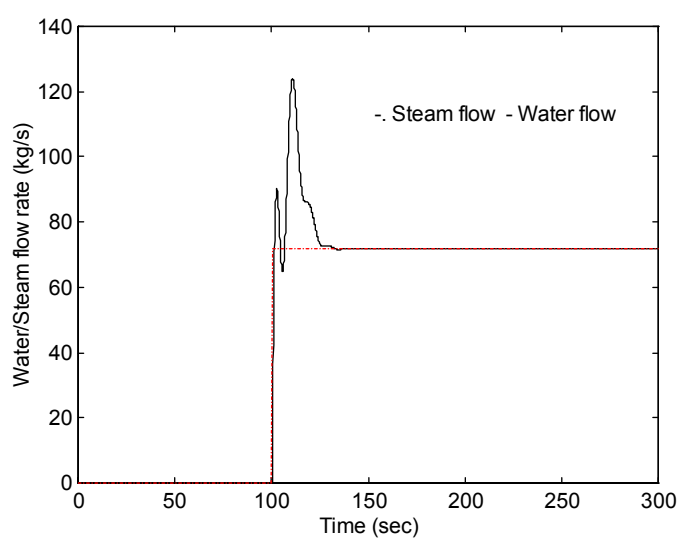

Fig. 17. Water/Steam flowrate change at 50\% power with $30 \%$ perturbation

\section{Conclusions}

A robust tracking controller is developed for a UTSG water level control system of a nuclear reactor. Automatic control of the water level in the steam generator from $0 \%$ to $100 \%$ of the load, and when large-scale perturbation occurs, is assured. It is shown that the tracking error can be reduced to zero if the parameter perturbation is bounded within a certain value. Simulation results are provided for some cases to validate the effectiveness of the controller. The control system matched the water flow to the steam flow, under various operating conditions and parameter uncertainties. It may be concluded from this that the control system enables the level to be kept within limits and that the transient phenomenon are overcome within reasonably short time. Further studies are needed to develop an adaptive state and parameter estimator for the UTSG system. 
Work on developing such an adapter has started and is not completed at this time. The steps towards developing a state estimator or observer is presented in the appendix.

\section{Acknowledgments}

This research is supported by an appointment to the Nuclear Regulatory Commission's (NRC) Historically Black Colleges and Universities Faculty Research Participation Program administered by the Oak Ridge Institute for Science and Education (ORISE) through a cooperative agreement between the U.S. Department of Energy and the U.S. Nuclear Regulatory Commission during the summer of 2001. The author would like to thank NRC ORISE for providing such an opportunity. The author is indebted to Drs. Kofi Korsah (supervisor), Jose March-Leuba, and Jim Mullens all of Instrumentation

\& Controls Division at Oak Ridge National Laboratory for their help, suggestions, and guidance in carrying out this project successfully. The ORNL portion of this work was funded by the U.S. Department of Energy Nuclear Energy Research Initiative (NERI) program.

\section{References:}

[1] Kothare, M. V., Mettler, B., and Morari, M., "Linear Parameter Varying Model Predictive Control for Steam Generator Level Control," Computers Chem. Engng., Vol. 21, 1997, pp. S861-S866.

[2] Kothare, M. V., Mettler, B., Morari, M., and Bendotti, P., "Level Control in the Steam Generator of a Nuclear Power Plant," IEEE Trans. Control System Technology, Vol. 8, No. 1, Jan. 2000, pp. 55-69.

[3] Menon, S. K. and Parlos, A. G., "Gain-Scheduled Nonlinear Control of U-Tube Steam Generator Water Level," Nuclear Science and Engineering, 111, 294-308 (1992).

[4] Na, M. G., and No, H. C., "Design of model reference adaptive control system for steam generators," Nuclear Engineering and Design, 122 (1990), 301-311.

[5] Na, M. G., "Design of steam generator water level controller via the estimation of flow errors," Ann. Nuclear Energy, Vol. 22, No. 6 pp. 367-376, 1995.

[6] Na, M. G., and No, H. C., "Design of adaptive observer-based controller for the water level of steam generator," Nuclear Engineering and Design, 135 (1992) 379-394.

[7] Schmitendorf, W. E., "Designing Stabilizing Controllers for Uncertain Systems Using the Riccati Equation Approach," IEEE Trans. Automatic Control, Vol. 33, No.4, pp. 376-379, April 1988.

[8] Peterson, I. R., "A Riccati Equation Approach to the Design of Stabilizing Controllers and Observers for a Class of Uncertain Linear Systems," IEEE Trans. Automatic Control, Vol. AC-30, No. 9, pp. 904-907, September, 1885.

[9] Schmitendorf, W. E. and Barmish, B. R., "Robust Asymptotic Tracking for Linear Systems with Unknown Parameters," Automatica, Vol. 22, No. 3, pp. 355-360, 1986. 
[10] Schmitendorf, W. E., "Design of Observer-Based Robust Stabilizing Controllers," Automatica, Vol. 24, No. 5, pp. 693-696, 1988.

[11] Athans, M., "The Role and Use of the Stochastic Linear-Quadratic-Gaussian Problem in Control System Design," IEEE Trans. Automatic Control, Vol. AC16, No. 6, December 1971.

[12] Ioannou, P. A. and Sun, J., "Robust Adaptive Control," Prentice-Hall, Inc., 1996.

[13] Sage, A. P. and White, C. C., "Optimum systems control," Prentice-Hall, Inc., 1977.

[14] Kim, M. K., Shin, M. H., and Chung, M. J., "A gain-scheduled $\mathrm{L}_{2}$ control to nuclear steam generator water level," Annals of Nuclear Energy 26 (1999) 905916. 


\section{Appendix}

\section{Observer Design:}

The implementation of the controller requires that the full state of the system is available. We like to estimate the states from the output measurements. By Kalman filter the optimal estimate $\hat{x}_{p}(t)$ of $x_{p q}(t)$ can be generated by

$$
\dot{\hat{x}}_{p}(t)=A_{0} \hat{x}_{p}(t)+B_{0} u_{p q}(t)+L\left[y_{p q}(t)-C_{0} \hat{x}_{p}(t)\right]
$$

The filter gain matrix $L$ is given by

$$
L=P_{2} C_{0}{ }^{T} R_{2}{ }^{-1}
$$

where $P_{2}$ is the solution of the algebraic Riccati equation

$$
A_{0} P_{2}+P_{2} A_{0}{ }^{T}+Q_{2}-P_{2} C_{0}{ }^{T} R_{2}{ }^{-1} C_{0} P_{2}=0
$$

The observer state equation can then be reduced to

$$
\dot{\hat{x}}_{p}(t)=\left(A_{0}-B_{0} K_{1}-L C_{0}\right) \hat{x}_{p}+L C_{p} x_{p}
$$

where $K_{1}$ is the gain required ensure output tracking, derived before.

The overall system will consist of the following equations

$$
\begin{aligned}
& \dot{x}_{p q}(t)=A_{p q} x_{p q}(t)+B_{p q} u_{p q}(t)+F_{p q} w(t)+H_{p q} y_{r} \\
& \dot{\hat{x}}_{p}(t)=\left(A_{0}-B_{0} K_{1}-L C_{0}\right) \hat{x}_{p}(t)+L C_{p} x_{p}(t) \\
& y_{p q}(t)=C_{p q} x_{p q}(t) \text { and } \\
& u_{p q}(t)=-K_{1} \hat{x}_{p}(t)-K_{2} q(t)
\end{aligned}
$$

The complete system may be represented by the block diagram shown below. 


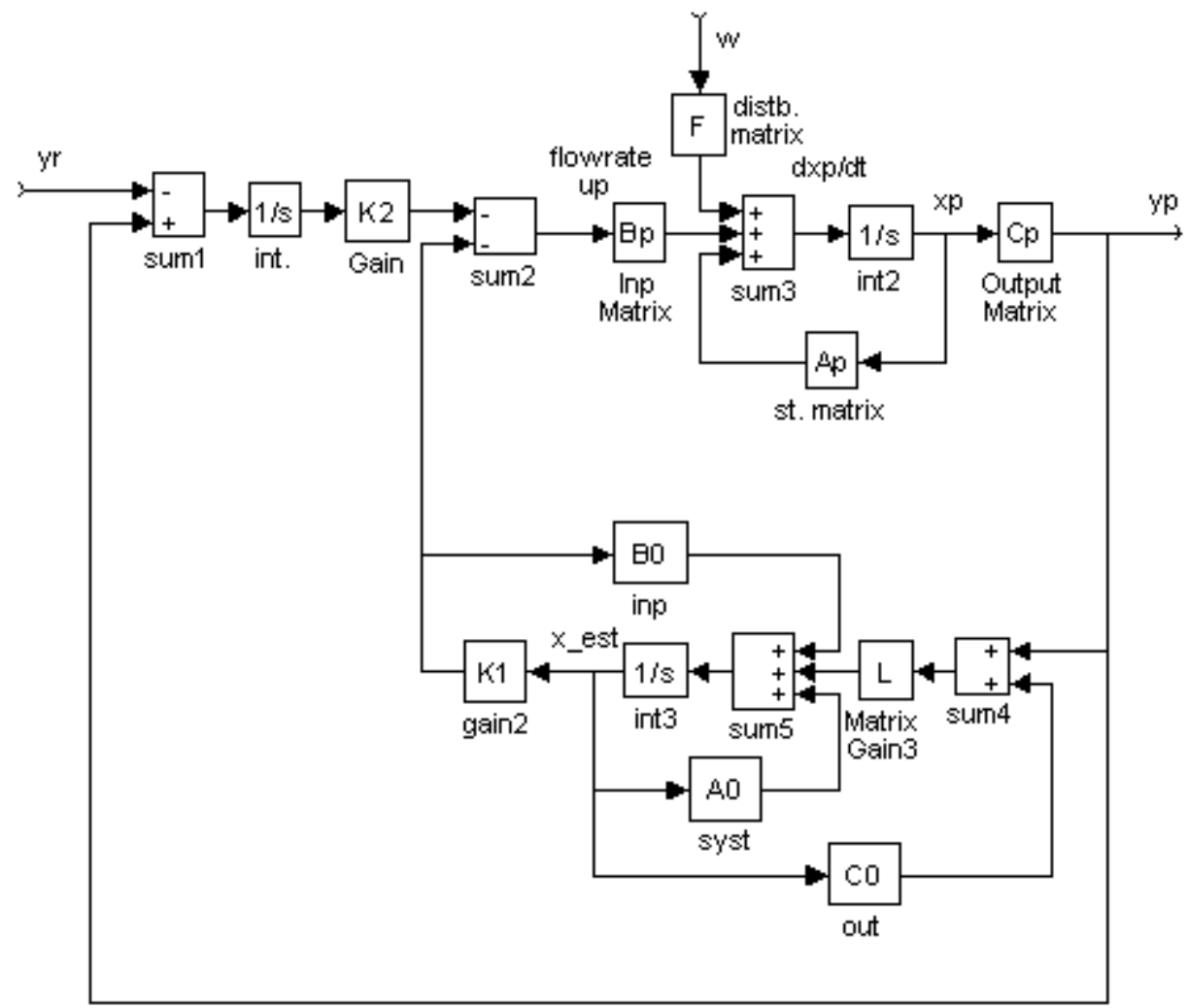

\section{Overall System:}

We define states as: $\stackrel{\Delta}{=}\left[\begin{array}{ll}x_{p q} & \hat{x}_{p}\end{array}\right]^{T}$

Then the system equations may be written as

$$
\begin{aligned}
& \dot{x}=A x+E w+G y_{r} \\
& y=C x
\end{aligned}
$$

where

$$
A=\left[\begin{array}{cc}
A_{p q} & -B_{p q} K_{1} \\
L C_{p q} & \left(A_{p q}-B_{p q} K_{1}-L C_{p q}\right)
\end{array}\right], \quad E=\left[\begin{array}{c}
F_{p q} \\
0
\end{array}\right], \quad G=\left[\begin{array}{c}
H_{p q} \\
0
\end{array}\right], \quad C=\left[\begin{array}{ll}
C_{p q} & 0
\end{array}\right]
$$

